\title{
Measuring Care-Related Quality of Life of Caregivers for Use in Economic Evaluations: CarerQol Tariffs for Australia, Germany, Sweden, UK, and US
}

\author{
Renske J. Hoefman ${ }^{1,2}$ (1) Job van Exel $^{2,3} \cdot$ Werner B. F. Brouwer ${ }^{2,4}$
}

Published online: 31 December 2016

(c) The Author(s) 2016. This article is published with open access at Springerlink.com

\begin{abstract}
Background Informal care is often not included in economic evaluations in healthcare, while the impact of caregiving can be relevant for cost-effectiveness recommendations from a societal perspective. The impact of informal care can be measured and valued with the CarerQol instrument, which measures the impact of informal care on seven important burden dimensions (CarerQol-7D) and values this in terms of general quality of life (CarerQol-VAS). The CarerQol can be included at the effect side of multi-criteria analyses of patient interventions or in cost-effectiveness or utility analysis of interventions targeted at caregivers.

Objective At present, utility scores based on relative utility weights for the CarerQol-7D are only available for the Netherlands. This study calculates CarerQol-7D tariffs for Australia, Germany, Sweden, UK, and US.

Methods Data were collected among the general population in Australia, Germany, Sweden, UK, and US by an Internet survey. Utility weights were collected with a discrete choice experiment with two unlabeled alternatives described in terms of the seven CarerQol-7D dimensions. An efficient experimental design with priors obtained from the Netherlands was used to create the choice sets. Data
\end{abstract}

Renske J. Hoefman

hoefman@bmg.eur.nl

1 Netherlands Institute for Health Services Research, PO Box 1568, Utrecht, The Netherlands

2 Institute of Health Policy and Management, Erasmus University Rotterdam, Rotterdam, The Netherlands

3 Erasmus School of Economics, Erasmus University Rotterdam, Rotterdam, The Netherlands

4 Institute for Medical Technology Assessment, Erasmus University Rotterdam, Rotterdam, The Netherlands was analyzed with a panel mixed multinomial logit model with random parameters.

Results In all five countries, the CarerQol-7D dimensions were significantly associated with the utility of informal care situations. Physical health problems were most strongly associated with the utility for informal care situations. The tariff was constructed by adding up the relative utility weights per category of all CarerQol-7D dimensions for each country separately.

Conclusion The CarerQol tariffs for Australia, Germany, Sweden, UK, and US facilitate the inclusion of informal care in economic evaluations.

\section{Key Points for Decision Makers}

The impact of providing informal care to family or friends is often overlooked when evaluating the costs and effects of interventions in healthcare. This article discusses the CarerQol instrument, which makes it possible to include the impact of caregiving on caregivers at the effect side of economic evaluations of healthcare interventions.

This article reports tariffs for the CarerQol instrument for five countries: Australia, Germany, Sweden, UK, and US.

\section{Introduction}

Economic evaluations of healthcare interventions increasingly support public decision making in healthcare, especially on new pharmaceuticals. Economic evaluations provide costeffectiveness information of healthcare by comparing the 
costs and effects of an intervention with its best alternative. Important in these evaluations is that all relevant costs and effects of interventions are considered. Which costs and effects are deemed relevant depends on the perspective of the economic evaluation [1-3]. It is often advocated that researchers conducting economic evaluations should apply a broad scope in their evaluations and consequently use the societal perspective [3,4]. This often implies that not only effects on patients and costs of formal healthcare use are relevant, but that economic evaluations should also consider the impact of the evaluated interventions on family and friends of patients [5-9]. In practice, most economic evaluations ignore (important aspects of) informal care, including those claiming to provide cost-effectiveness recommendations from a societal perspective $[10,11]$. Informal care constitutes a large part of the total care provided to patients and the elderly in many countries $[12,13]$. Although providing informal care can be fulfilling for caregivers, lending care can also be both mentally and physically straining [14-18]. Without consideration of the impact of informal care, the results of economic evaluations may be biased with the risk of leading to sub-optimal policy recommendations.

The impact of caregiving on informal caregivers can be included in economic evaluations by measuring and valuing the effects on caregivers in terms of their 'care-related quality of life' $[19,20]$. Tariffs can be applied to calculate care-related quality-of-life scores of caregivers for use in economic evaluations. This may be useful when evaluating interventions for patients requiring informal care (e.g., because of their chronic conditions or age-related health problems). In these situations where patient interventions are evaluated, care-related quality of life cannot be directly added to patient effects in a costeffectiveness analysis (CEA) or cost-utility analysis (CUA). However, care-related quality of life can be included next to and separate from patient effects in a cost-consequence or multi-criteria analysis. In other situations, the focus may be on evaluating interventions for informal carers (e.g., respite care programs). Caregiver utilities are central here. Care-related quality of life can then serve as the primary outcome measure and be included at the effect side of a CEA or CUA [20,21]. The CarerQol-7D instrument produces such care-related quality-of-life scores of caregivers with the use of 'tariffs'. The resulting care-related quality-of-life scores take differences in the importance of problems that caregivers can face into account. The CarerQol-7D measures two positive dimensions of caregiving (fulfilment and support) and five problem dimensions (relational problems, mental health, physical health, financial problems, and problems combining daily activities with caring), each with three response categories ('no', 'some', 'a lot') (see Fig. 1).

At this moment, a tariff for calculating standard (carerelated) utility scores for all CarerQol-7D states is only available for the Netherlands [22]. This tariff is based on the preferences of the general public of the Netherlands for the $2187\left(3^{7}\right)$ caregiving states described by the CarerQol7D instrument. The practical application of the CarerQol instrument in scientific studies could be facilitated by population-specific tariffs for other countries than the Netherlands, as is common in health state valuations [23-25]. This study provides tariffs for the CarerQol instrument for five countries: Australia, Germany, Sweden, $\mathrm{UK}$, and US.

\section{Methods}

\subsection{Data}

Data were collected in August 2014 in Australia, Germany, Sweden, UK, and US. A web-based questionnaire was distributed by an Internet survey company to respondents representative of the adult population in each of these five countries in terms of age, sex, and educational level. Per country at least 500 respondents were recruited for the study. This number was motivated by efficiency measures of the design used in this choice experiment [26]. The number of respondents included in the data analysis was: 551 (Australia), 562 (Germany), 548 (Sweden), 552 (UK), and 550 (US). Descriptive statistics of the study samples can be found in Table 1.

\subsection{Discrete Choice Experiment}

Discrete choice experiments were conducted to develop tariff sets for the CarerQol-7D for Australia, Germany, Sweden, UK, and US. The methodology applied here is based on the estimation of the CarerQol tariff for The Netherlands [22]. Respondents were instructed to imagine that while completing the survey they provided care or support to a loved one as a result of an illness, disability, or infirmity of old age. They were also asked to keep the same care recipient in mind during the whole experiment. After completing the choice tasks, respondents were asked for the level of difficulty of the choice tasks and their familiarity with informal care giving, or with caregivers in their own circles of family and friends.

Choice sets were constructed with an efficient experimental design with priors from the CarerQol-7D tariff set for the Netherlands [22] to calculate standards errors of the parameters as statistically efficient as possible to increase reliability of the results with smaller sample sizes [27-29]. The efficient experimental design contained 40 choice sets, ${ }^{1}$

\footnotetext{
${ }^{1}$ Minimum number of independent choice probabilities: $S \times(J-$ $1) \geq K$, where $S$ is the number of choice sets, $J$ is the number of alternatives, and $K$ is the degrees of freedom of parameters.
} 
Table 1 Background information of respondents in mean (standard deviation) or percentages

\begin{tabular}{|c|c|c|c|c|c|c|}
\hline \multirow[t]{2}{*}{ Characteristics } & & \multirow{2}{*}{$\begin{array}{l}\text { Australia }(n=551) \\
\text { Mean }(\mathrm{SD}) \text { or } \%\end{array}$} & \multirow{2}{*}{$\begin{array}{l}\text { Germany }(n=562) \\
\text { Mean }(\mathrm{SD}) \text { or } \%\end{array}$} & \multirow{2}{*}{$\begin{array}{l}\text { Sweden }(n=548) \\
\text { Mean }(\mathrm{SD}) \text { or } \%\end{array}$} & \multirow{2}{*}{$\begin{array}{l}\text { UK } \\
(n=552) \\
\text { Mean (SD) or } \%\end{array}$} & \multirow{2}{*}{$\begin{array}{l}\text { US }(n=550) \\
\text { Mean }(\mathrm{SD}) \text { or } \%\end{array}$} \\
\hline & & & & & & \\
\hline \multirow[t]{7}{*}{ Age (years) } & & $45.5(16.4)$ & $46.7(16.3)$ & $47.3(17.5)$ & $46.6(16.7)$ & $45.8(16.9)$ \\
\hline & $18-24$ & 12.3 & 11.2 & 12.4 & 12.1 & 13.3 \\
\hline & $25-34$ & 18.0 & 15.3 & 15.7 & 17.0 & 17.5 \\
\hline & $35-44$ & 19.6 & 20.6 & 16.8 & 17.8 & 17.5 \\
\hline & $45-54$ & 18.3 & 17.1 & 17.0 & 17.6 & 19.3 \\
\hline & $55-64$ & 14.7 & 14.4 & 16.2 & 15.0 & 15.6 \\
\hline & $65+$ & 17.1 & 21.4 & 21.9 & 20.3 & 16.9 \\
\hline \multirow[t]{2}{*}{ Sex } & Female & 51.2 & 51.6 & 50.9 & 51.6 & 51.5 \\
\hline & Male & 48.8 & 48.4 & 49.1 & 48.4 & 48.6 \\
\hline \multirow[t]{3}{*}{ Educational level } & Low & 1.1 & 21.2 & 17.9 & 20.7 & 13.3 \\
\hline & Middle & 67.7 & 55.7 & 49.6 & 23.0 & 28.2 \\
\hline & High & 31.2 & 23.1 & 32.5 & 56.3 & 58.6 \\
\hline \multirow[t]{3}{*}{ Paid work } & Full time & 35.0 & 42.0 & 39.4 & 43.7 & 37.3 \\
\hline & Part time & 19.8 & 14.2 & 10.0 & 14.7 & 13.1 \\
\hline & No & 45.2 & 43.8 & 50.6 & 41.7 & 49.6 \\
\hline \multirow[t]{3}{*}{ Partner } & Yes & 54.1 & 61.7 & 56.8 & 62.0 & 55.1 \\
\hline & No & 44.8 & 37.5 & 40.5 & 37.1 & 44.2 \\
\hline & Did not state & 1.1 & 0.7 & 2.7 & 0.9 & 0.7 \\
\hline
\end{tabular}

$S D$ standard deviation

which were blocked over four groups of respondents, i.e., in the survey, ten choice sets were presented to each respondent. The utility functions consisted of two dummy variables per attribute (reference level: no for the two positive attributes of the CarerQol-7D, a lot for the five negative attributes), interaction terms for all attribute combinations, and a constant term for the first alternative in the choice set. The dummy variables were treated as Bayesian priors with a normal distribution using mean and standard error of the multinomial logit (MNL) model of the tariff for the CarerQol-7D in the Netherlands, allowing parameter values to be both negative and positive (see "Appendix", Table 5). The efficient experimental design was optimized for D-efficiency in the basic multinomial logit model [28] calculating mean values using 1000 Halton draws [30]. The efficient experimental design was constructed in Ngene (ChoiceMetrics, Australia).

In this discrete choice experiment, respondents were asked to choose between two unlabeled hypothetical informal care situations (see Fig. 2 for an example). These hypothetical informal care situations were described by a combination of the seven attributes and three levels of the CarerQol-7D: (1) fulfilment with carrying out your care tasks, (2) relational problems with the care receiver, (3) problems with your own mental health, (4) problems combining your care tasks with your daily activities, (5) financial problems because of your care tasks, (6) support with carrying out your care tasks, and (7) problems with your own physical health. The levels of these attributes were 'no', 'some', and 'a lot'. Color coding was used to aid visual representation of the information: positive attribute levels were displayed in green text, the negative levels in red text, and the intermediate levels in orange text [31]. The choice sets were presented in random order to the respondents.

In addition, at the start of the questionnaire, information was gathered on the respondents' age, sex, highest attained educational level, marital status, and current employment status.

The questionnaire was translated in Swedish by native speakers involved in research among informal caregivers and in German by Mapi values. The original English version of the CarerQol instrument [19] was translated into Swedish and German using forward-backward translation. The English translation was performed by the authors and checked for accuracy by native speakers and informal care researchers from Australia, UK, and US. This resulted in separate questionnaires for each of the three countries, which were largely identical but contained some countryspecific adaptations to spelling and wording (e.g., "neighbours' or 'neighbors' in the examples provided with the seven dimensions of the CarerQol).

\subsection{Analyses}

The data were analyzed with a panel mixed multinomial logit (MMNL) model, allowing for the presence of unobservable preference heterogeneity in the population 
Fig. 1 The CarerQol instrument

We would like to form an impression of your caregiving situation. Please tick a box to indicate which description best fits your caregiving situation at the moment.

Please tick only one box per description: 'no', 'some' or 'a lot of'.

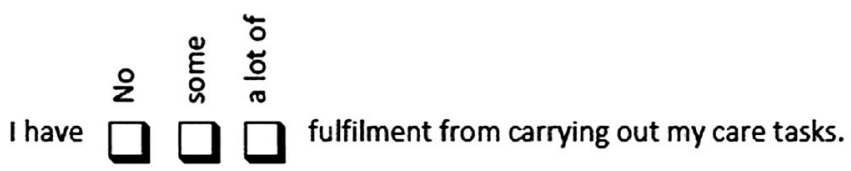

I have relational problems with the care receiver (e.g., he/she is very demanding or behaves differently; we have communication problems).

I have problems with my own mental health (e.g., stress, fear, gloominess, depression, concern about the future).

I have problems combining my care tasks with my own daily activities (e.g. household activities, work, study, family, leisure activities).

I have $\square \square \square$ financial problems because of my care tasks.

I have $\square \square \square$ support with carrying out my care tasks, when I need it (e.g., from family, friends, neighbours, acquaintances).

I have problems with my own physical health (e.g., more often sick, tiredness, physical stress).

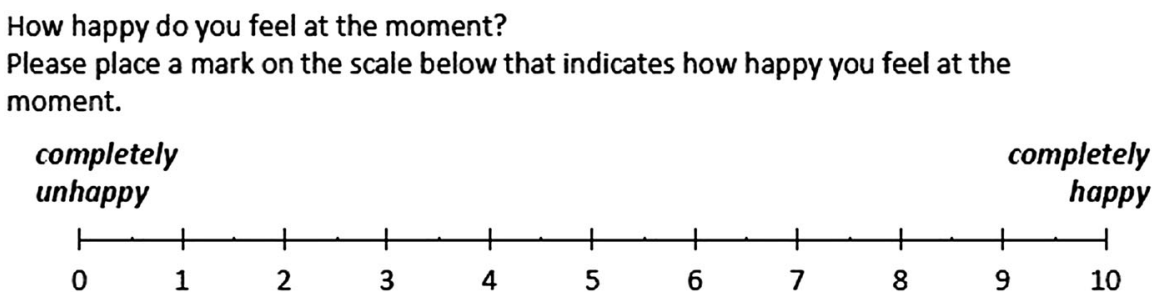

(random parameters) and the correlation of responses across observations (panel structure) [26, 32]. Likelihood ratio tests were used to construct the model specification, in particular considering whether the model should include: (1) an alternative specific constant, (2) random or fixed parameters, (3) interaction effects of the attributes, and (4) collapsed attribute levels. These tests were performed for each country separately.

\subsection{CarerQol Tariff}

The tariff for the CarerQol-7D was based on individualspecific parameters. These parameters were calculated by randomly assigning the unconditional distribution of the panel MMNL model (population level estimates of the panel MMNL model) over a hypothetical sample of 10,000 individuals with bootstrap sampling [26]. Next, the individual-specific parameter estimates from the bootstrap sampling were averaged. The mean parameter values were rescaled to represent the CarerQol-7D tariff ranging from 0 (worst informal care situation) to 100 (best informal care situation). The standard errors of the tariff were calculated by dividing the standard errors of the MMNL parameters by the same total score. Analyses were performed in Nlogit 5.0 (Econometric Software Inc., Plainview, New York, US). Finally, for the purpose of illustration, CarerQol-7D utility scores were calculated for six caregiving situations described by the CarerQol-7D using the tariffs of Australia, Germany, Sweden, UK, and US. These caregiving states were selected given their prevalence in a large dataset of 
Fig. 2 Example of choice set. Note: in the choice-sets, the levels were color coded: the best level per attribute (i.e., 'no' for the negative attributes and 'a lot of' for the positive attributes) was printed in green, the middle level in orange, and the worst level in red
Which caregiving situation do you prefer?

\begin{tabular}{|l|}
\hline \multicolumn{1}{|c|}{ Caregiving situation A } \\
\hline $\begin{array}{l}\text { You have no fulfilment from carrying out your } \\
\text { care tasks }\end{array}$ \\
\hline $\begin{array}{l}\text { You have a lot of relational problems with the } \\
\text { care receiver }\end{array}$ \\
\hline $\begin{array}{l}\text { You have some problems with your own } \\
\text { mental health }\end{array}$ \\
\hline $\begin{array}{l}\text { You have some problems combining your care } \\
\text { tasks with your own daily activities }\end{array}$ \\
\hline $\begin{array}{l}\text { You have a lot of financial problems because } \\
\text { of your care tasks }\end{array}$ \\
\hline $\begin{array}{l}\text { You receive a lot of support with carrying out } \\
\text { your care tasks, when you need it }\end{array}$ \\
\hline $\begin{array}{l}\text { You have some problems with your own } \\
\text { physical health }\end{array}$ \\
\hline \hline
\end{tabular}

\begin{tabular}{|l|}
\hline \multicolumn{1}{|c|}{ Caregiving situation B } \\
\hline $\begin{array}{l}\text { You have a lot of fulfilment from carrying out } \\
\text { your care tasks }\end{array}$ \\
\hline $\begin{array}{l}\text { You have a lot of relational problems with the } \\
\text { care receiver }\end{array}$ \\
\hline $\begin{array}{l}\text { You have a lot of problems with your own } \\
\text { mental health }\end{array}$ \\
\hline $\begin{array}{l}\text { You have a lot of problems combining your } \\
\text { care tasks with your own daily activities }\end{array}$ \\
\hline $\begin{array}{l}\text { You have some financial problems because of } \\
\text { your care tasks }\end{array}$ \\
\hline $\begin{array}{l}\text { You receive no support with carrying out your } \\
\text { care tasks, when you need it }\end{array}$ \\
\hline $\begin{array}{l}\text { You have a lot of problems with your own } \\
\text { physical health }\end{array}$ \\
\hline \hline \\
\hline
\end{tabular}

informal caregivers in the Netherlands [17]. The six CarerQol-7D states ranged from less to more desirable caregiving situations (see Table 4). The CarerQol-7D utility scores of the five countries of this study and of the Netherlands, computed using the tariffs presented in Hoefman et al. [22], are presented in a radar plot created in Microsoft Excel (US).

\section{Results}

\subsection{Utility of Informal Care Situations}

The relative weights of the seven dimensions of the CarerQol-7D for the five countries are presented in Table 2. For all countries, all the seven CarerQol-7D dimensions were significantly associated with the utility of informal care situations. In each of the five countries, the utility of informal care situations was significantly higher when this situation was more attractive in terms of more fulfilment and support and no or less caregiving problems.

In all five countries, informal care-related utility was relatively strongly influenced by the presence of physical health problems. In the majority of countries, mental health problem and financial problems also had a relatively strong influence on care-related utility. In general, two CarerQol7D dimensions (problems with daily activities and support) were relatively weakly associated with the utility of informal care situations.

\subsection{CarerQol Tariff}

Table 3 presents the CarerQol tariffs for Australia, Germany, Sweden, UK, and US. Total utility scores for
CarerQol states can be calculated by adding up the tariff per category of the seven CarerQol-7D dimensions. For example, an informal care situation in which the caregiver has "no fulfilment, some relational problems, a lot of mental health problems, some problems combining daily activities, no financial problems, some support and a lot of physical health problems" (CarerQol-7D state 2 in Table 4) represents utility scores of 35.6, 43.5, 40.3, 35.9, and 36.0 in Australia, Germany, Sweden, UK, and US, respectively.

For the purpose of illustration, the radar plot (Fig. 3) presents the CarerQol-7D scores of six caregiving situations of Australia, Germany, Sweden, UK, US, and the Netherlands. In general, the CarerQol-7D scores of all countries resemble each other fairly well. The ranking of the six states according to their utility value is identical across countries, and the range of utility values per state does not overlap with the following better state.

\section{Discussion}

This study derived preference weights for the seven dimensions of the CarerQol-7D instrument in Australia, Germany, Sweden, UK, and US to calculate countryspecific tariffs for the CarerQol for use in economic evaluations. In line with the results of the study conducted in the Netherlands [22], all seven dimensions of the CarerQol7D were important for the utility value of informal care situations in the general population in the five countries. As expected, people prefer caregiving situations characterized by more positive experiences from caring (more fulfilment and social support) and fewer relational, health, and financial problems or fewer problems combining care with 
Table 2 Panel MMNL model per country

\begin{tabular}{|c|c|c|c|c|c|c|c|c|c|c|c|c|c|c|c|}
\hline \multirow{2}{*}{$\begin{array}{l}\text { CarerQol-7D } \\
\text { dimension }\end{array}$} & \multicolumn{3}{|c|}{ Australia } & \multicolumn{3}{|c|}{ Germany } & \multicolumn{3}{|c|}{ Sweden } & \multicolumn{3}{|l|}{ UK } & \multicolumn{3}{|l|}{ US } \\
\hline & Coef. & $\mathrm{SD}^{\mathrm{a}}$ & $p$ value & Coef. & $\mathrm{SD}^{\mathrm{a}}$ & $p$ value & Coef. & $\mathrm{SD}^{\mathrm{a}}$ & $p$ value & Coef. & $\mathrm{SD}^{\mathrm{a}}$ & $p$ value & Coef. & $\mathrm{SD}^{\mathrm{a}}$ & $p$ value \\
\hline \multicolumn{16}{|c|}{ Fulfilment (ref. no) } \\
\hline Some & 1.17 & 0.73 & 0.000 & 0.95 & d & 0.000 & 1.37 & 1.74 & 0.000 & 1.11 & 2.25 & 0.000 & 0.57 & 1.25 & 0.000 \\
\hline A lot & 1.45 & 1.23 & 0.000 & 1.20 & d & 0.000 & 1.53 & 1.97 & 0.000 & 1.45 & 2.84 & 0.000 & 0.85 & 1.32 & 0.000 \\
\hline \multicolumn{16}{|c|}{ Relational problems (ref. a lot) } \\
\hline No & 1.13 & 0.65 & 0.000 & 1.38 & 1.37 & 0.000 & 1.96 & 2.25 & 0.000 & 1.39 & 2.04 & 0.000 & 0.82 & 1.31 & 0.000 \\
\hline Some & 0.78 & 0.60 & 0.000 & 0.87 & 1.17 & 0.000 & 1.45 & 1.88 & 0.000 & 0.98 & 1.49 & 0.000 & 0.52 & 1.24 & 0.000 \\
\hline \multicolumn{16}{|c|}{ Mental health problems (ref. a lot) } \\
\hline No & 1.82 & 1.31 & 0.000 & 1.07 & 1.41 & 0.000 & 2.16 & 2.11 & 0.000 & 2.68 & 2.48 & 0.000 & 1.72 & 1.58 & 0.000 \\
\hline Some & 1.20 & 1.11 & 0.000 & 1.00 & 0.79 & 0.000 & 1.71 & 1.81 & 0.000 & 1.86 & 1.71 & 0.000 & 1.22 & 1.06 & 0.000 \\
\hline \multicolumn{16}{|c|}{ Problems with daily activities (ref. a lot) } \\
\hline No & 0.84 & 0.81 & 0.000 & 0.73 & 1.01 & 0.000 & 0.98 & 1.83 & 0.000 & 0.83 & 1.77 & 0.000 & 0.41 & 1.00 & 0.000 \\
\hline Some & 0.42 & 0.60 & 0.000 & 0.48 & 0.81 & 0.000 & 0.69 & 1.44 & 0.000 & 0.36 & 1.74 & 0.035 & b & & \\
\hline \multicolumn{16}{|c|}{ Financial problems (ref. a lot) } \\
\hline No & 1.49 & 1.49 & 0.000 & 1.64 & 1.72 & 0.000 & 1.88 & 2.15 & 0.000 & 1.96 & 2.62 & 0.000 & 1.27 & 1.55 & 0.000 \\
\hline Some & 1.05 & 0.92 & 0.000 & 1.06 & 1.28 & 0.000 & 1.24 & 1.43 & 0.000 & 1.33 & 1.81 & 0.000 & 0.89 & 1.16 & 0.000 \\
\hline \multicolumn{16}{|c|}{ Support (ref. no) } \\
\hline Some & 0.50 & $\mathrm{~d}$ & 0.000 & 0.51 & 1.03 & 0.000 & 0.52 & 1.09 & 0.000 & 0.77 & 1.21 & 0.000 & 0.39 & 0.79 & 0.000 \\
\hline A lot & $\mathrm{c}$ & & 0.000 & 0.73 & 1.08 & 0.000 & 0.63 & 1.39 & 0.000 & 0.92 & 1.25 & 0.000 & 0.44 & 0.84 & 0.000 \\
\hline \multicolumn{16}{|c|}{ Physical health problems (ref. a lot) } \\
\hline No & 1.79 & 1.84 & 0.000 & 1.21 & 1.93 & 0.000 & 2.21 & 2.25 & 0.000 & 2.05 & 2.68 & 0.000 & 1.65 & 1.83 & 0.000 \\
\hline Some & 1.44 & 1.39 & 0.000 & 1.07 & 1.58 & 0.000 & 1.68 & 1.69 & 0.000 & 1.70 & 2.10 & 0.000 & 1.12 & 1.50 & 0.000 \\
\hline
\end{tabular}

Coef. coefficient, $M M N L$ mixed multinomial logit, ref. reference level, $S D$ standard deviation

${ }^{a}$ Attribute-specific SD of Cholesky matrix

${ }^{b}$ No/some are merged

c Some/a lot are merged

${ }^{\mathrm{d}}$ Non-random coefficients in model

other activities. The most important dimension of utility for informal care situations was the physical health of caregivers, while the least important dimensions were problems combining caregiving with other activities and support with caregiving tasks. These findings were in line with those from the Netherlands [22].

However, comparisons between countries remain difficult, given that differences in the data could be explained by genuine issues, such as country-specific attitudes towards informal caregiving or random error [33]. In addition, despite the careful translation process, small differences may have crept into the different language versions of the questionnaire. Moreover, the model specifications between countries differed (e.g., non-random coefficients for the CarerQol-7D dimension of support in Australia and the dimension of fulfilment in Germany).

Some other limitations of this study need to be mentioned. In all five countries, heterogeneity in the preferences for caregiving situations was observed. In contrast to the tariff in the Netherlands, no interaction effects of the seven dimensions of caregiving burden could significantly explain the utility values of caregiving situations in Australia, Germany, Sweden, UK, or US. Other strategies to explain heterogeneity in the choice data, such as subgroup analyses, have not been attempted because the aim of this study was to derive a general tariff for the CarerQol-7D that could be applied among all types of caregivers and study settings. Hence, we attempted to resemble the methodology commonly used and advocated for deriving health state preferences. Moreover, there is discussion in the literature as to which preferences are relevant in the context of economic evaluations: those of the group affected by the intervention or those of the general public [34]. To resemble the methodology of health state values, we collected preferences of the general public to calculate CarerQol tariffs.

Furthermore, it should also be stressed that an Internet panel was used to collect data. Although the use of the Internet has become common for most members of 
Table 3 CarerQol tariffs

\begin{tabular}{|c|c|c|c|c|c|c|c|}
\hline \multirow[t]{2}{*}{ Country } & \multirow[t]{2}{*}{ CarerQol-7D dimensions } & \multicolumn{2}{|l|}{ No } & \multicolumn{2}{|l|}{ Some } & \multicolumn{2}{|l|}{ A lot } \\
\hline & & Tariff & SE & Tariff & SE & Tariff & SE \\
\hline \multirow[t]{7}{*}{ Australia } & Fulfilment & 0.0 & 0.0 & 13.0 & 1.5 & 16.1 & 1.9 \\
\hline & Relational problems & 12.5 & 1.2 & 8.7 & 1.1 & 0.0 & 0.0 \\
\hline & Mental health problems & 20.1 & 1.6 & 13.2 & 1.2 & 0.0 & 0.0 \\
\hline & Problems with daily activities & 9.5 & 1.2 & 4.8 & 1.0 & 0.0 & 0.0 \\
\hline & Financial problems & 16.5 & 1.6 & 11.5 & 1.2 & 0.0 & 0.0 \\
\hline & Support & 0.0 & 0.0 & 5.6 & 0.9 & 5.6 & 0.9 \\
\hline & Physical health problems & 19.8 & 1.7 & 15.7 & 1.4 & 0.0 & 0.0 \\
\hline \multirow[t]{7}{*}{ Germany } & Fulfilment & 0.0 & 0.0 & 11.9 & 1.7 & 15.1 & 2.1 \\
\hline & Relational problems & 17.8 & 1.7 & 10.6 & 1.5 & 0.0 & 0.0 \\
\hline & Mental health problems & 13.5 & 1.7 & 12.7 & 1.4 & 0.0 & 0.0 \\
\hline & Problems with daily activities & 9.2 & 1.5 & 6.0 & 1.3 & 0.0 & 0.0 \\
\hline & Financial problems & 20.3 & 2.1 & 13.4 & 1.6 & 0.0 & 0.0 \\
\hline & Support & 0.0 & 0.0 & 6.6 & 1.3 & 9.1 & 1.4 \\
\hline & Physical health problems & 15.1 & 1.9 & 13.2 & 1.7 & 0.0 & 0.0 \\
\hline \multirow[t]{7}{*}{ Sweden } & Fulfilment & 0.0 & 0.0 & 12.1 & 2.0 & 13.9 & 2.4 \\
\hline & Relational problems & 16.9 & 2.1 & 13.0 & 1.9 & 0.0 & 0.0 \\
\hline & Mental health problems & 19.0 & 2.2 & 15.3 & 1.8 & 0.0 & 0.0 \\
\hline & Problems with daily activities & 8.7 & 1.7 & 6.0 & 1.4 & 0.0 & 0.0 \\
\hline & Financial problems & 16.5 & 2.1 & 11.1 & 1.7 & 0.0 & 0.0 \\
\hline & Support & 0.0 & 0.0 & 4.8 & 1.2 & 5.6 & 1.4 \\
\hline & Physical health problems & 19.5 & 2.2 & 14.9 & 1.9 & 0.0 & 0.0 \\
\hline \multirow[t]{7}{*}{ UK } & Fulfilment & 0.0 & 0.0 & 10.1 & 2.1 & 13.0 & 2.6 \\
\hline & Relational problems & 12.0 & 1.8 & 8.8 & 1.6 & 0.0 & 0.0 \\
\hline & Mental health problems & 23.9 & 2.3 & 16.5 & 1.7 & 0.0 & 0.0 \\
\hline & Problems with daily activities & 7.4 & 1.6 & 3.1 & 1.5 & 0.0 & 0.0 \\
\hline & Financial problems & 17.2 & 2.1 & 11.5 & 1.7 & 0.0 & 0.0 \\
\hline & Support & 0.0 & 0.0 & 6.9 & 1.4 & 8.1 & 1.4 \\
\hline & Physical health problems & 18.4 & 2.3 & 15.0 & 1.9 & 0.0 & 0.0 \\
\hline \multirow[t]{7}{*}{ US } & Fulfilment & 0.0 & 0.0 & 7.6 & 1.9 & 11.7 & 2.3 \\
\hline & Relational problems & 11.6 & 1.8 & 7.0 & 1.7 & 0.0 & 0.0 \\
\hline & Mental health problems & 23.8 & 2.2 & 17.0 & 1.7 & 0.0 & 0.0 \\
\hline & Problems with daily activities & 5.8 & 1.5 & 5.8 & 1.5 & 0.0 & 0.0 \\
\hline & Financial problems & 18.0 & 2.0 & 12.5 & 1.7 & 0.0 & 0.0 \\
\hline & Support & 0.0 & 0.0 & 5.3 & 1.4 & 6.2 & 1.5 \\
\hline & Physical health problems & 23.0 & 2.3 & 15.8 & 1.9 & 0.0 & 0.0 \\
\hline
\end{tabular}

SE standard error

Table 4 CarerQol-7D states of radar plot (Fig. 3)

\begin{tabular}{lllllll}
\hline CarerQol-7D dimension & State 1 & State 2 & State 3 & State 4 & State 5 & State 6 \\
\hline Fulfilment & A lot & No & Some & Some & Some & A lot \\
Relational problems & A lot & Some & No & Some & Some & No \\
Mental health problems & A lot & A lot & Some & Some & No & No \\
Problems with daily activities & A lot & Some & Some & Some & No & No \\
Financial problems & A lot & No & Some & Some & No & No \\
Support & A lot & Some & No & Some & Some & Some \\
Physical health problems & A lot & A lot & A lot & Some & No & No \\
\hline
\end{tabular}




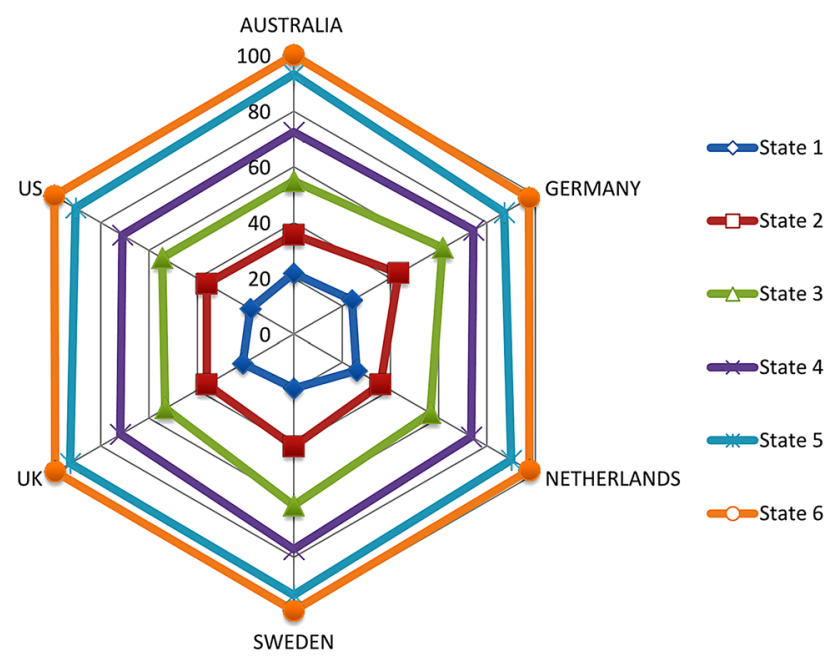

Fig. 3 Radar plot CarerQol-7D scores per country (states 1-6)

society, including the elderly [35], the study sample might be somewhat selective because of the use of an Internet panel. Moreover, persons with a low educational level are somewhat underrepresented in four out of five countries in the study (UK, US, Australia, and Sweden). Here, a note should also be made on the country-specific classifications of educational level in the Internet panels per country. For example, the classification applied in the Internet panel in Australia is relatively strict in defining a low educational level including only persons with primary education, while the categorization in other countries is somewhat broader. In US, for example, persons that were in high school but did not graduate are classified in the lowest educational level. As a result, the number of persons with a low educational level in Australia is relatively low compared with the other countries in the study.

A limitation for the use of the CarerQol in studies with international comparisons of informal care is the selection of relatively comparable Western countries in this article. It would be interesting to study preferences for caregiving in a broader range of countries with different healthcare systems and/or cultural values towards family care, such as countries in southern Europe where, in general, the role of the family is more central in caregiving [12].

Informal care can be included in economic evaluations in different ways. If informal care is considered, it usually is included at the cost side of economic evaluations. In this way, little attention is being paid to the impact that caregiving can have on caregivers. Hence, it is recommended to measure and value the impact of caregiving on caregivers in terms of quality of life $[7,36]$. Care-related quality-of-life values can be used as an outcome in different types of economic evaluations of healthcare programs. In the often-used CEA/CUA, the CarerQol can only be applied when interventions targeted at caregivers are evaluated. Care-related quality of life could then serve as the main outcome of interest. When evaluating patient interventions, the CarerQol cannot be used in the CEA/CUA, where health (-related quality of life) is the outcome of interest. In these types of economic evaluations, the effect of caregiving on caregivers can be measured in terms of health-related quality of life with the same health utility instruments as applied to measure health-related quality of life in patients. The health utilities of informal caregivers can then be added to those of patients at the effect side of the CEA/CUA. The risk of double counting the effects of caregivers seems to be low. Evidence suggests that respondents include the effects of a health state on loved ones in different ways in health state valuations. Hence, on average, the effect on loved ones seems not significantly to influence health state valuations [37]. Although the CarerQol measures both physical and mental health of caregivers, care-related quality of life also encompasses other important dimensions of caregiving and therefore CarerQol-7D utility scores cannot be summated with common health-related utilities measured in patients.

It should also be noted here that, in contrast to common health state valuations, the duration component of the valued good is not included. In further research, investigating how the time component could be added to valuation exercises and its influence on outcomes would be interesting and relevant. Alternatively, the CarerQol can be used as an outcome measure in a multi-criteria analysis of patient interventions. Care-related quality of life of caregivers can then be used as a measure of the effect of a patient intervention next to other effect measures, such as health-related quality of life in patients. In this way, policymakers are explicitly informed about the consequences of a patient intervention on caregivers. A more detailed discussion on how informal care can be included in economic evaluations can be found in Koopmanschap et al. [21] and in Hoefman et al. [20, 38].

\section{Conclusions}

This article presents utility values for the CarerQol instrument for Australia, Germany, Sweden, UK, and US. These population-specific tariffs enhance the practical application of the instrument in evaluation studies, and ultimately facilitate informed public decision making in healthcare, aiming to increase the welfare of all, including informal carers. 
Acknowledgements We are grateful to Karen Kuhlthau, $\mathrm{PhD}$, Astrid Stephan, MScN, Nikki McCaffrey, PhD, Prof. Anders Wimo, Sven Neelsen, $\mathrm{PhD}$, and Hareth Al-Janabi, PhD, for assistance with the translations of the questionnaires, and to the Erasmus Happiness Economics Research Organisation for their financial support for the data collection and analysis.

Data Availability Statement Data and syntax file are available from the authors upon request.

\section{Compliance with Ethical Standards}

Funding Financial support for this study was provided in part by a grant from Erasmus Happiness Economics Research Organisation. The funding agreement ensured the authors' independence in designing the study, interpreting the data, and writing and publishing the report.

Conflict of interest JE and WB were part of the team that developed the CarerQol instrument. RH, JE, and WB have conducted a number of validation studies of the CareQol. Otherwise, RH, JE, and WB report no conflicts of interest.

Consent for publication For this type of study in online panels, no ethics approval is required in the Netherlands. Respondents were informed about the purpose of the study, the content of the questionnaire, and how the anonymity of respondents was organized. Next, respondents were asked for their consent to use the data they provided for the purpose of this study. After completing the questionnaire, respondents were asked to confirm their consent, and informed their data would be deleted immediately otherwise.

Author contributions RH created the design for the choice experiment, developed the survey, coordinated the data collection, performed the analyses, and drafted the manuscript. JE developed the survey, supervised the collection and analysis of the data, and provided comments to draft versions of the manuscript. WB supervised the study and provided comments to the draft versions of the manuscript. All authors read and approved the final manuscript.

Open Access This article is distributed under the terms of the Creative Commons Attribution-NonCommercial 4.0 International License (http://creativecommons.org/licenses/by-nc/4.0/), which permits any noncommercial use, distribution, and reproduction in any medium, provided you give appropriate credit to the original author(s) and the source, provide a link to the Creative Commons license, and indicate if changes were made.

\section{Appendix}

See Table 5 .
Table 5 Conditional logistic model of CarerQol-7D states in The Netherlands [22]

\begin{tabular}{lllll}
\hline & & Coef. & SE & $p$ value \\
\hline Fulfilment (ref. no) & Some & 0.89 & 0.05 & 0.000 \\
Relational problems (ref. a lot) & A lot & 1.28 & 0.05 & 0.000 \\
& No & 0.86 & 0.05 & 0.000 \\
Mental health problems (ref. a lot) & Some & 0.62 & 0.04 & 0.000 \\
Problems with daily activities (ref. a lot) & No & 0.88 & 0.06 & 0.000 \\
& Some & 0.67 & 0.05 & 0.000 \\
Financial problems (ref. a lot) & No & 0.64 & 0.04 & 0.000 \\
Support (ref. no) & Some & 0.34 & 0.04 & 0.000 \\
Physical health problems (ref. a lot) & No & 0.85 & 0.05 & 0.000 \\
Mental no $\times$ physical no & Some & 0.62 & 0.04 & 0.000 \\
& Some & 0.33 & 0.04 & 0.000 \\
\hline
\end{tabular}

Coef. coefficient, $S E$ standard error, ref. reference level

${ }^{a}$ Minimum number of independent choice probabilities: $S \times(J-1) \geq K$, where $S$ is the number of choice sets, $J$ is the number of alternatives, and $K$ is the degrees of freedom of parameters 


\section{References}

1. Brazier J, Ratcliffe J, Salomon JA, Tsuchiya A. Measuring and valuing health benefits for economic evaluation. Oxford, New York: Oxford University Press; 2007.

2. Brouselle A, Lessard C. Economic evaluation to inform health care decision-making: promise, pitfalls and a proposal for an alternative path. Soc Sci Med. 2011;72(6):832-9.

3. Drummond MF, Sculpher MJ, Torrance GW, et al. Methods for the economic evaluation of health care programmes. Oxford: Oxford University Press; 2005.

4. Gold MR, Siegel JE, Russell LB, Weinstein M. Cost-effectiveness in health and medicine. New York: Oxford University Press; 1996.

5. Van Exel J, Bobinac A, Koopmanschap M, Brouwer W. The invisible hands made visible: recognizing the value of informal care in healthcare decision-making. Exp Rev Pharmacoecon Outcomes Res. 2008;8(6):557-61.

6. Dixon S, Walker M, Salek S. Incorporating carer effects into economic evaluation. Pharmacoeconomics. 2006;24(1):43-53.

7. Brouwer WB, Koopmanschap MA. On the economic foundations of CEA: ladies and gentlemen, take your positions! J Health Econ. 2000;19(4):439-59.

8. Davidson T, Levin LA. Is the societal approach wide enough to include relatives? Incorporating relatives' costs and effects in a cost-effectiveness analysis. Appl Health Econ Health Policy. 2010;8(1):25-35.

9. Al-Janabi H, McCaffrey N, Ratcliffe J. Carer preferences in economic evaluation and healthcare decision making. Patient. 2013;6(4):235-9.

10. Krol M, Papenburg J, van Exel J. Does including informal care in economic evaluations matter? A systematic review of inclusion and impact of informal care in cost-effectiveness studies. Pharmacoeconomics. 2015;33(2):123-35.

11. Stone PW, Chapman RH, Sandberg EA, et al. Measuring costs in cost-utility analyses: variations in the literature. Int $\mathrm{J}$ Technol Assess Health Care. 2000;16(1):111-24.

12. Riedel M, Kraus M. Informal care provision in Europe: regulation and profile of providers. ENEPRI Research Report No. 96, Brussels; 2011.

13. Colombo F, Llena-Nozal A, Mercier J, Tjadens F. Help wanted? Providing and paying for long-term care. Paris: OECD Publishing; 2011.

14. Brouwer WB, Van Exel NJ, Van den Berg B, et al. Process utility from providing informal care: the benefit of caring. Health Policy. 2005;74(1):85-99.

15. Beach SR, Schulz R, Yee JL, Jackson S. Negative and positive health effects of caring for a disabled spouse: longitudinal findings from the caregiver health effects study. Psychol Aging. 2000;15(2):259.

16. Joling KJ, van Hout HPJ, Schellevis FG, et al. Incidence of depression and anxiety in the spouses of patients with dementia: a naturalistic cohort study of recorded morbidity with a 6-year follow-up. Am J Geriatr Psych. 2010;18(2):146.

17. Hoefman RJ, van Exel J, Brouwer WB. Measuring the impact of caregiving on informal carers: a construct validation study of the CarerQol instrument. Health Qual Life Outcomes. 2013;11(1):173-86.

18. Adelman RD, Tmanova LL, Delgado D, et al. Caregiver burden: a clinical review. J Am Med Assoc. 2014;311(10):1052-60.
19. Brouwer WB, Van Exel NJ, Van Gorp B, Redekop WK. The CarerQol instrument: a new instrument to measure care-related quality of life of informal caregivers for use in economic evaluations. Qual Life Res. 2006;15(6):1005-21.

20. Hoefman RJ, van Exel J, Brouwer W. How to include informal care in economic evaluations. Pharmacoeconomics. 2013;31(12):1105-19.

21. Koopmanschap MA, Van Exel JN, Van den Berg B, Brouwer WB. An overview of methods and applications to value informal care in economic evaluations of healthcare. Pharmacoeconomics. 2008;26(4):269-80.

22. Hoefman RJ, Van Exel NJA, Rose JM, et al. A discrete choice experiment to obtain a tariff for valuing informal care situations measured with the CarerQol instrument. Med Decis Making. 2014;34(1):84-96.

23. Björk S, Norinder A. The weighting exercise for the Swedish version of the EuroQol. Health Econ. 1999;8(2):117-26.

24. Lamers LM, McDonnell J, Stalmeier PF, et al. The Dutch tariff: results and arguments for an effective design for national EQ-5D valuation studies. Health Econ. 2006;15(10):1121-32. doi:10. 1002/hec.1124.

25. Dolan P. Modeling valuations for EuroQol health states. Med Care. 1997;35(11):1095-108.

26. Hensher DA, Rose JM, Greene WH. Applied choice analysis: a primer. Cambridge: Cambridge University Press; 2005.

27. Bliemer MCJ, Rose JM. Experimental design influences on stated choice outputs: an empirical study in air travel choice. Transp Res A Policy Pract. 2011;45(1):63-79.

28. Rose JM, Bliemer MCJ. Constructing efficient stated choice experimental designs. Transp Rev. 2009;29(5):587-617.

29. Carlsson F, Martinsson P. Design techniques for stated preference methods in health economics. Health Econ. 2003;12(4):281-94.

30. Bliemer MCJ, Rose JM, Hess S. Approximation of Bayesian efficiency in experimental choice designs. J Choice Model. 2008;1(1):98-127.

31. Balcombe K, Fraser I, McSorley E. Visual attention and attribute attendance in multi-attribute choice experiments. J Appl Econ. 2015;30(3):447-67.

32. Hensher DA, Greene WH. The mixed logit model: the state of practice. Transportation. 2003;30(2):133-76.

33. Norman R, Cronin P, Viney R, et al. International comparisons in valuing EQ-5D health states: a review and analysis. Value Health. 2009;12(8):1194-200.

34. Versteegh M, Brouwer W. Patient and general public preferences for health states: a call to reconsider current guidelines. Soc Sci Med. 2016;165:66-74.

35. Statistics N. More older people active online. 2011. http:// www.cbs.nl/nl-NL/menu/themas/vrije-tijd-cultuur/publicaties/ artikelen/archief/2011/2011-3537-wm.htm. Accessed 23 Aug 2012.

36. Brouwer WBF, Van Exel NJA, Tilford MJ. Incorporating caregiver and family effects in economic evaluations of child health. In: Ungar WJ, editor. Economic evaluation in child health. Oxford: Oxford University Press; 2010.

37. Krol M, Attema AE, van Exel J, Brouwer W. Altruistic preferences in time tradeoff: consideration of effects on others in health state valuations. Med Decis Making. 2016;36(2):187-98.

38. Hoefman RJ, Van Exel NJA, Brouwer WBF. iVICQ: iMTA valuation of informal care questionnaire. Rotterdam: iBMG/ iMTA; 2011. 